\title{
Catalytic Performance of Phosphorus Incorporated HZSM-5 in Coupling Transformation of Methanol with 1-butene to Propylene
}

\author{
HAIFENG TIAN, YONGYONG NAN, JINLONG LV, FEI ZHA*' XIAOHUA TANG, \\ YUE CHANG, XIAOJUN GUO \\ Northwest Normal University, College of Chemistry \& Chemical Engineering, Lanzhou 730070, Gansu, China
}

\begin{abstract}
Directly incorporated phosphorus species into the framework of HZSM-5 zeolite (H[P, Al]ZSM-5) was successfully synthesized by the facile hydrothermal method. It was characterized by employing XRD, ICP-OES, SEM, FT-IR, $\mathrm{N}_{2}$ adsorption-desorption, $\mathrm{NH}_{3}-\mathrm{TPD}, \mathrm{XPS}$ and TG-DTA, respectively. The effects of the phosphorus species content, temperature, WHSV, and the molar ratio of methanol/1-butene in coupling transformation of methanol with 1-butene to propylene catalyzed by H[P, Al]-ZSM-5 in a fixed bed reactor were studied systematically. Tests have suggested the acid content and specific surface area of H[P, Al]-ZSM-5 are reduced. Under the condition of reaction temperature at $550^{\circ} \mathrm{C}$, molar ratio of methanol/1-butene to 1.0 , reaction pressure at $0.1 \mathrm{MPa}$ and $\mathrm{WHSV}=3.53 \mathrm{~h}^{-1}$, the P-modified HZSM-5 zeolite (with the $\mathrm{P}_{2} \mathrm{O}_{5}$ molar composition of 0.4 )the selectivity and yield of propylene are $35.6 \%$ and $32.5 \%$, respectively.
\end{abstract}

Keywords: The P-modified HZSM-5 zeolite, Coupling ,methanol, 1-butene, Propylene

\section{Introduction}

Light olefins (such as propylene and ethene) are the important feedstock in the petrochemical industry, which are usually used to produce polyethylene, butadiene, etc. The research on enhancing the production of propylene has been a hot topic in recent years both in academic and industrial applications, which in turn promote the production process such as the cracking of hydrocarbons, fluid catalytic cracking (FCC), and methanol to olefin (MTO) [1, 2]. However, these processes determined its lower yield of propylene and lower catalytic lifetime due to propylene acts as the byproducts and cannot satisfy the huge market demand with a fast growth rate [3]. Therefore, it is meaningful to search for another alternative routine to intensify the production of propylene.

MTO process has increasingly attracted a lot of attention and undergoes a rapid developments since the late 1970s [4]. MTO process is an exothermic reaction, meanwhile, the $\mathrm{C}_{4}$ hydrocarbon catalytic cracking process is an endothermic reaction. In order to improve the target of aimed product and make full use of energy balance, it is quite promising to propose coupling transformation of methanol with 1butene. This coupling reaction can alleviate problems such as excess methanol capacity and low $\mathrm{C}_{4}$ hydrocarbon utilization.

The acidic zeolites are often used in the petrochemical industry as catalyst and absorbents due to their high porous structure, adjustable acidity, shape selectivity and three-dimensional porous structure $[5,6]$. Generally, HZSM-5 zeolite was often the alternate choice to be used in coupling transformation of methanol with 1-butene to propylene. However, the strong acidity density on the parent HZSM-5 can accelerate the rate of coke formation [7]. Therefore, the pure HZSM-5 zeolite is easily deactivated during the reaction because there are bulky molecules accumulated in pores or surfaces, thus blocked the pore entrances and exhibited the lower yield of propylene and lower catalytic lifetime [8]. Understanding the relationship between the acidity and activity, it is easy to design the effective catalyst to get the higher selectivity of propylene. Li et al [9] found that the coupling conversion of ethylene and methanol could be promoted after reduce in the acidic strength or the number of acid sites over modified HZSM5 zeolite. Lu et al. [10] showed that ZSM-5 with a high Si/Al ratio could reduce the total acidity, there-

*email: zhafei@nwnu.edu.cn 
fore, side reactions such as hydrogen transfer reactions are inhibited and showed a higher yield of aromatics and alkanes. Hence, the enhance of coke resistance of HZSM-5 zeolite is a meaningful way to improve the catalytic performance and stability. So far,researchers have made efforts to design the effective ZSM-5 to be used in coupling methanol with 1-butene [11]. The acidity, morphology and structure of the zeolite could be adjusted by promoter impregnation and metal doping, which shows good catalytic activity. Several promoters have been applied over HZSM-5 zeolite [12-14].

Blasco et al [14]. found that phosphorous added in the form of either $\mathrm{NH}_{4} \mathrm{H}_{2} \mathrm{PO}_{4}$ or $\mathrm{H}_{3} \mathrm{PO}_{4}$ into ZSM5 can increase its hydrothermal stability. In addition, Zhao et al. [15]. observed that the propylene selectivity could be enhanced after ZSM-5 modified by phosphorous species although causing some structural damage and reducing in strong acid sites. Based on the above mentioned possible reasons, in this study, different content of P species was introduced to HZSM-5 by the isomorphous substitution method. Phosphorus incorporated HZSM-5 was used as a catalyst in coupling transformation of methanol with 1-butene in a fixed-bed reactor in detail [16].

\section{Materials and methods}

\subsection{Materials}

Ethyl orthosilicate (28 wt\% of the $\left.\mathrm{SiO}_{2}\right)$, aluminium nitrate nonahydrate $\left(\mathrm{Al}\left(\mathrm{NO}_{3}\right) 9 \mathrm{H}_{2} \mathrm{O}, 99 \%\right)$, tetrapropyl ammonium hydroxide (TPAOH, $25 \%$ in water), phosphoric acid $\left(\mathrm{H}_{3} \mathrm{PO}_{4}, 85.0 \%\right)$, sodium hydroxide $(\mathrm{NaOH}, 99 \%)$ were used without further purification, respectively.

\subsection{Synthesis of P-modified HZSM-5}

In a traditional hydrothermal synthesis process, the gel with the molar concentration of $97 \mathrm{SiO}_{2}: 1$ $\mathrm{Al}_{2} \mathrm{O}_{3}: 79$ TPAOH : $5 \mathrm{Na}_{2} \mathrm{O}: 2414 \mathrm{H}_{2} \mathrm{O}$ was obtained by mixing of ethyl orthosilicate, aluminum nitrate, tetrapropyl ammonium hydroxide (TPAOH), sodium hydroxide and deionized water. Then, the mixture was transformed into an autoclave and crystallized at $170^{\circ} \mathrm{C}$ for $24 \mathrm{~h}$. The product was washed, dried at $80^{\circ} \mathrm{C}$ overnight, and then calcined at $550^{\circ} \mathrm{C}$ for $5 \mathrm{~h}$. The obtained $\mathrm{Na}$-formed zeolites were converted into $\mathrm{H}$-formed zeolites by sequential ion-exchanged three times in $1.0 \mathrm{M} \mathrm{NH}{ }_{4} \mathrm{Cl}$ solution at $80^{\circ} \mathrm{C}$ for $2 \mathrm{~h}$ to obtain HZSM-5 zeolite. For the P-modified catalyst, the typical synthesis procedure was with the molar concentration of $97 \mathrm{SiO}_{2}: 0.6 \mathrm{Al}_{2} \mathrm{O}_{3}: 79$ TPAOH : $5 \mathrm{Na}_{2} \mathrm{O}: 2414 \mathrm{H}_{2} \mathrm{O}: \mathrm{X} \mathrm{P}_{2} \mathrm{O}_{5}(\mathrm{X}=0.2,0.4,0.6,0.8)$, and the synthesis was similar to that of HZSM-5. The obtained product was labelled as H[P, Al]-ZSM$5(\mathrm{X})$.

\subsection{Catalyst characterization}

The samples were characterized by X-ray diffraction (XRD) on a D/Max-2400 Rigaku diffraction with $\mathrm{CuK} \alpha$ radiation under an instrumental setting of $40 \mathrm{kV}$ and $60 \mathrm{~mA}$. Scanning electron microscopy (SEM) was carried out on a German Zeiss ULTRA plus. Nitrogen adsorption/desorption measurements were carried out on an AUTOSORB-1-MP. The Fourier transform infrared (FT-IR) spectra were recorded on a DIGILAB FTS-3000 spectrophotometer. The acidity of the samples was measured by temperature-programmed desorption of ammonia ( $\mathrm{NH}_{3}-\mathrm{TPD}, \mathrm{MFTP} 3060$ ). Thermo-gravimetric (TG) analysis was performed on a Perkin-Elmer TG/DTA-6300 with a rate of $10^{\circ} \mathrm{C} / \mathrm{min}$. The elemental composition of the catalyst samples were measured by inductively coupled plasma optical emission spectroscopy (ICP-OES, ICP OES730).

\subsection{Catalyst activity evaluation}

The coupling reaction of methanol with 1-butene was performed in a fixed-bed reactor apparatus (ICES1H3F, Better Work Intelligent Technology Co. Ltd, Xiamen, China). Before the reaction was carried out, the catalyst was pretreated under $\mathrm{N}_{2}(30 \mathrm{~mL} / \mathrm{min})$ at a desirable experiment temperature. $\mathrm{CH}_{3} \mathrm{OH}$ was injected by means of springe pump and 1-butene was also fed by springe pump. The vapour phase product was analyzed on a GC-9790 gas chromatograph equipped with $\mathrm{KB}-\mathrm{Al}_{2} \mathrm{O}_{3} / \mathrm{Na}_{2} \mathrm{SO}_{4}$ capillary column $(30 \mathrm{~m} \times 0.32 \mathrm{~mm} \times 15 \mu \mathrm{m})$ and FID detector. It was mainly used to detect $\mathrm{C}_{1}-\mathrm{C}_{4}$ and 
$\mathrm{C}_{5}{ }^{+}$. Methanol was detected by TCD detector with a specification of $3 \mathrm{~m} \times 3 \mathrm{~mm}$ Porapak Q packed column. The methanol conversion and product yield and selectivity were calculated according to the balance principle of carbon atoms number with equations (1) - (3), respectively.

Conv ersiorf methanol(wt. \%) = methanoleed - methanobff $/$ methanolleed $\times 100 \%$

Conv ersiorøf 1-Butene(wt.\%)=1-Butenefeed-1-Buteneoff $/ 1-B u t e n \in e e d \times 100 \%$

Selectiv jik $(w t . \%)=A i \times n i / \sum A i \times n i \times 100 \%$

Y ield $(w t . \%)=$ conv ersiorof 1 -Butene $\times$ selectiv iti $\times 100 \%$

where Ais the peak area of the corresponding product on the gas chromatogram and $\mathrm{n}$ represents the number of carbon atoms of the product $i$.

\section{Results and discussions}

\subsection{Characterization of samples}

Figure 1 presented the XRD patterns of fresh and spent P-modified HZSM-5 zeolite, which exhibits the typical diffraction peaks of MFI topology. Moreover, it can be seen that no diffraction peaks of $\mathrm{P}$ species are observed on catalyst isomorphously substituted by $\mathrm{P}$ species, demonstrating it is highly dispersed into the zeolite and does not destroy the MFI structure of HZSM-5. As shown in Figure 1, the relative crystallinity of $\mathrm{H}[\mathrm{P}, \mathrm{Al}]-\mathrm{ZSM}-5(0.2), \mathrm{H}[\mathrm{P}, \mathrm{Al}]-\mathrm{ZSM}-5(0.4), \mathrm{H}[\mathrm{P}, \mathrm{Al}]-\mathrm{ZSM}-5(0.6)$ and $\mathrm{H}[\mathrm{P}, \mathrm{Al}]-$ ZSM-5(0.8) are $48 \%, 272 \%, 110 \%$ and $87 \%$ compared to the parent HZSM-5, respectively, which indicates that the crystallization process could be affected after $\mathrm{P}$ species incorporated into the structure of HZSM-5 and then forms the different length of P-O bond compared to the Al-O bond from the parent HZSM-5. In addition, the relative crystallinity of typical peaks in XRD patterns of $\mathrm{H}[\mathrm{P}, \mathrm{Al}]-\mathrm{ZSM}-5(0.4)$ and $\mathrm{H}[\mathrm{P}, \mathrm{Al}]-\mathrm{ZSM}-5(0.6)$ is increased compared to parent HZSM-5, this may be due to the phosphorus modification has the effect of stabilizing the framework of zeolite and inhibits the loss of framework Al during the hydrothermal synthesis process. Moreover, it can be seen that the typical MFI diffraction peaks shift after HZSM-5 modified with $P$ species, which may be due to its change in the lattice spacing "d" of value with the $\mathrm{Al}$ atoms from the zeolite structure substituted with $\mathrm{P}$ atoms [17].

Figure 2 showed the morphological structure and particle size of all catalysts. Compared to HZSM5 zeolite, An uniformly spherical catalysts are almost not changed after ZSM- 5 was modified by P species and $\mathrm{H}[\mathrm{P}, \mathrm{Al}]-\mathrm{ZSM}-5$ exhibit a smooth particle external surfaces except the H[P, Al]-ZSM-5(0.8) which further implies that the morphological structure of HZSM-5 is not damaged after modification with $\mathrm{P}$ species. Besides, the average crystal size of five catalysts is not nearly changed with the increase of $\mathrm{P}$ species content.

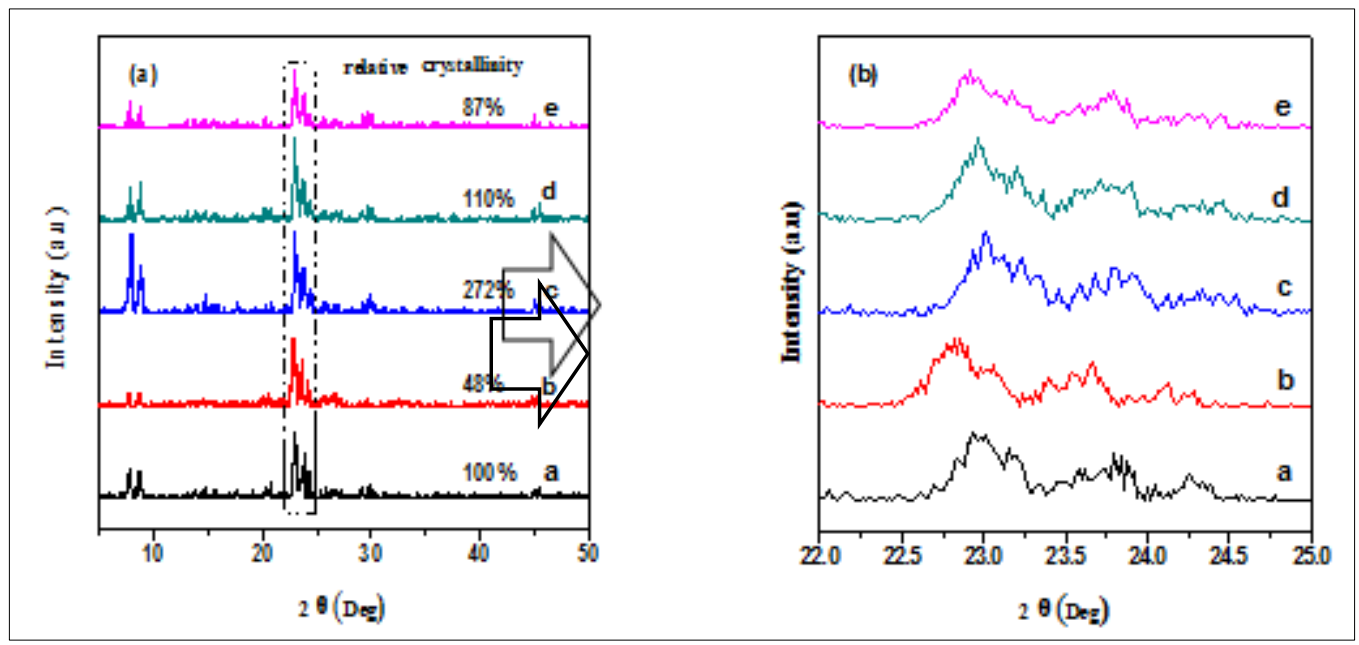

Figure 1. XRD patterns of (a) HZSM-5, (b) H[P, Al]-ZSM-5(0.2),

(c) H[P, Al]-ZSM-5(0.4), (d) H[P, Al]-ZSM-5(0.6) and (e) H[P, Al]-ZSM-5(0.8) 


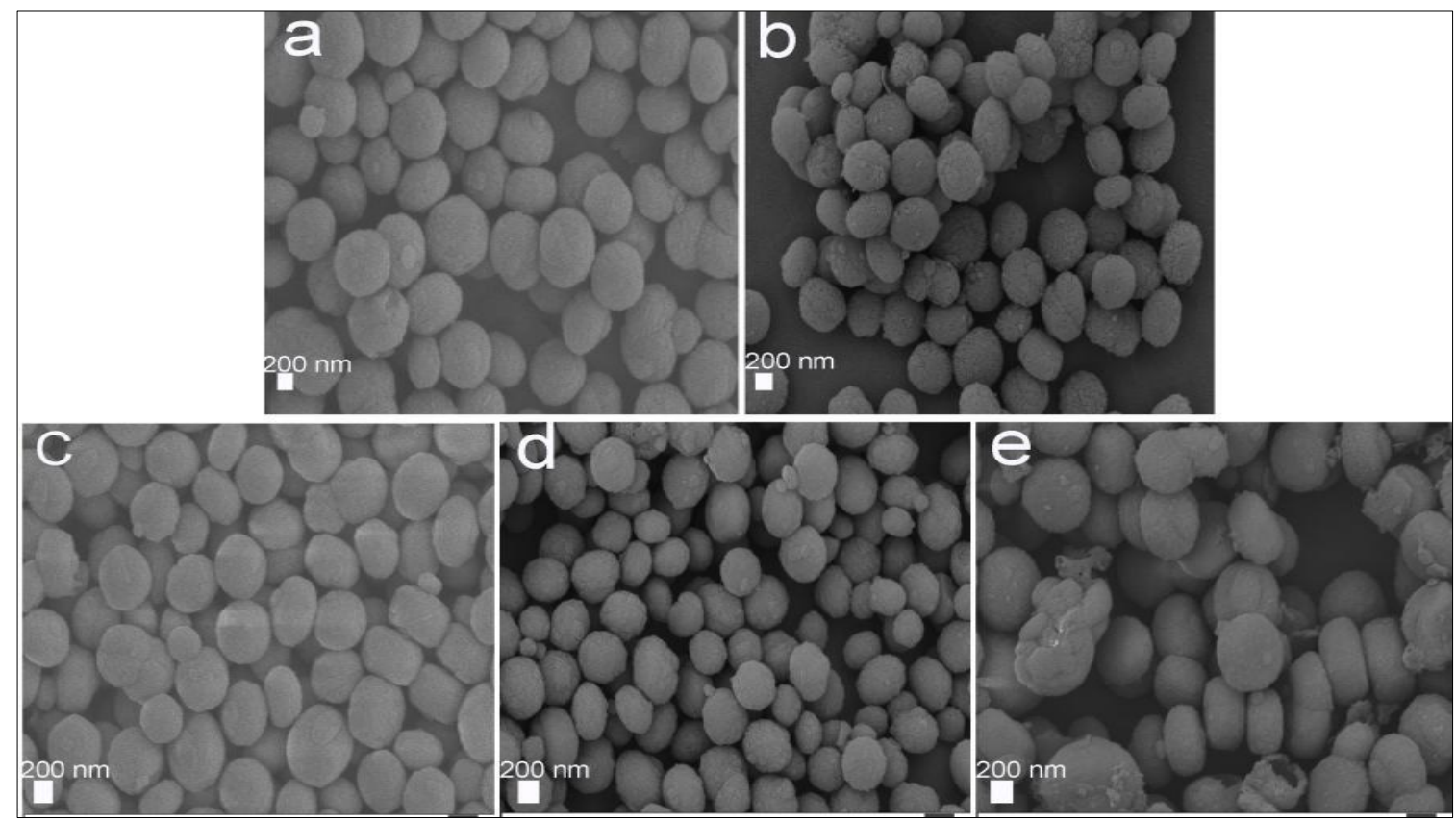

Figure 2. SEM microscopy images of (a) HZSM-5, (b) H[P, Al]-ZSM-5(0.2), (c) $\mathrm{H}[\mathrm{P}, \mathrm{Al}]-\mathrm{ZSM}-5(0.4)$, (d) H[P, Al]-ZSM-5(0.6) and (e) H[P, Al]-ZSM-5(0.8)

Figure S1 showed the FT-IR spectra of HZSM-5, H[P, Al]-ZSM-5(0.2) H[P, Al]-ZSM-5(0.4), H[P, Al]-ZSM-5(0.6) and H[P, Al]-ZSM-5(0.8) in the range of $4000-3100 \mathrm{~cm}^{-1}$ and $1800-400 \mathrm{~cm}^{-1}$. Four catalysts show the same characteristic vibrational bands. Two sharp peaks at 800 and $1100 \mathrm{~cm}^{-1}$ are assigned to the symmetric stretching of external and internal linkages, respectively. The intensity of the peak at $1225 \mathrm{~cm}^{-1}$ represents the presence of a structure containing four five-rings chains. The bands near at 450 and $550 \mathrm{~cm}^{-1}$ represent the internal tetrahedron units of $\mathrm{SiO}_{4}, \mathrm{AlO}_{4}$, and the five-membered rings of the ZSM-5 zeolite [18]. FT-IR in the range of 3000-3800 $\mathrm{cm}^{-1}$ characterizes the surface hydroxyl $\left(\mathrm{OH}^{-}\right)$groups, which further indicates the structure of HZSM-5 zeolite is not destroyed after modified with $\mathrm{P}$ species [19]. In addition, the vibrational band at 634 and $592 \mathrm{~cm}^{-1}$ are obvious on $\mathrm{H}[\mathrm{P}, \mathrm{Al}]-\mathrm{ZSM}-$ 5(0.2), H[P, Al]-ZSM-5(0.4), H[P, Al]-ZSM-5(0.6) and H[P, Al]-ZSM-5(0.8) compared to HZSM-5 zeolite, which may be attributed to that the phosphorous species is successfully introduced into the structure of HZSM-5 zeolite.

The $\mathrm{N}_{2}$ adsorption-desorption isotherms of five catalysts were illustrated in Figure 3. The calculation results of the corresponding parameters were listed in Table S1. It can be seen that parent HZSM-5 zeolite shows the type $\mathrm{I} \mathrm{N}_{2}$ adsorption-desorption isotherm with the micropore volume of $0.10 \mathrm{~cm}^{3} \cdot \mathrm{g}^{-1}$ and the surface area of $379 \mathrm{~m}^{2} \cdot \mathrm{g}^{-1}$, which is a typical microporous material. However, the surface area of HZSM-5 zeolite modified by $\mathrm{P}$ species is reduced, which may be due to the successful introduction of $\mathrm{P}$ species into HZSM-5 zeolite and replacing $\mathrm{Al}$ and causing some pore blockage. $\mathrm{H}[\mathrm{P}, \mathrm{Al}]-\mathrm{ZSM}$ 5(0.2), H[P, Al]-ZSM-5(0.4), H[P, Al]-ZSM-5(0.6) and H[ P, Al]-ZSM-5 (0.8) with a surface area of $315,377,343$, and $348 \mathrm{~m}^{2} \cdot \mathrm{g}^{-1}$, respectively. It can be seen that these five isotherms show the similar increasing behavior within $\mathrm{p} / \mathrm{p}_{0}<0.2$ and show typical type I with an $\mathrm{H}_{4}$-shaped hysteresis loop, which is typical microporous material [20,21]. Moreover, five catalysts show a sharply increasing hysteresis loop at $\mathrm{p} / \mathrm{p}_{0}$ higher than 0.8 . 


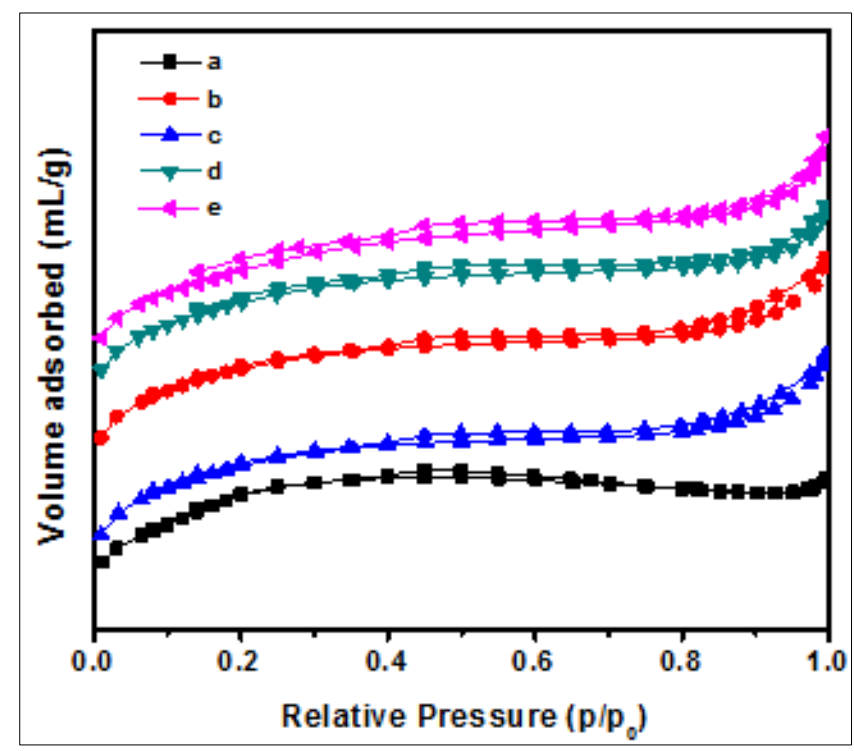

Figure 3. $\mathrm{N}_{2}$ adsorption-desorption isotherms of (a) HZSM-5, (b) $\mathrm{H}[\mathrm{P}, \mathrm{Al}]-\mathrm{ZSM}-5(0.2)$, (c) $\mathrm{H}[\mathrm{P}, \mathrm{Al}]-$ ZSM-5(0.4), (d) H[P, Al]-ZSM-5(0.6) and (e) H[P, Al]-ZSM-5(0.8)

The $\mathrm{NH}_{3}$-TPD curves of HZSM-5 modified with the $\mathrm{P}$ species were shown in Figure 4, which is used to characterize the distribution of acid strength and concentration. All catalysts exhibit three desorption peaks centered about at 95,163 and $361^{\circ} \mathrm{C}$, which are corresponding to weak, medium and strong acid sites, respectively. The amount of $\mathrm{NH}_{3}$ desorbed from the catalysts was listed in Table $\mathrm{S} 2$. It can be seen that the acid sites strength on HZSM-5 zeolite and P-modified HZSM-5 zeolite have differences among three kinds of acid sites, which may be due to differences of the amount of $\mathrm{P}$ in place of $\mathrm{Al}$ in the zeolite framework and thus affecting the concentration of acid sites of catalysts [22]. Most interesting, it can be found that the concentration of weak acid sites of HZSM-5 zeolite is increased after P species introduced into HZSM-5 structure by isomorphous substitution method, which may be due to the change of molar the ratio of $\mathrm{Si} / \mathrm{Al}$ [23]. In addition, compared to parent HZSM-5 zeolite, the concentration of medium and strong acid sites of H[P, Al]-ZSM-5(0.4) is decreased in maximium value from 112 and 150 (a.u./g) to 65 and 88 (a.u./g), indicating that phosphorus species is interacted with the acid sites on external surfaces of HZSM-5 [24] and engenders adjacent $\mathrm{OH}^{-}$groups by isomorphously substituted of $\mathrm{P}$ with $\mathrm{Al}$ [25]. However, considering the whole aspect of the analysis from the $\mathrm{NH}_{3}$-TPD test, changes on three desorption peaks are significant, implying that three kinds of acid sites are closely influenced by $\mathrm{P}$ species.

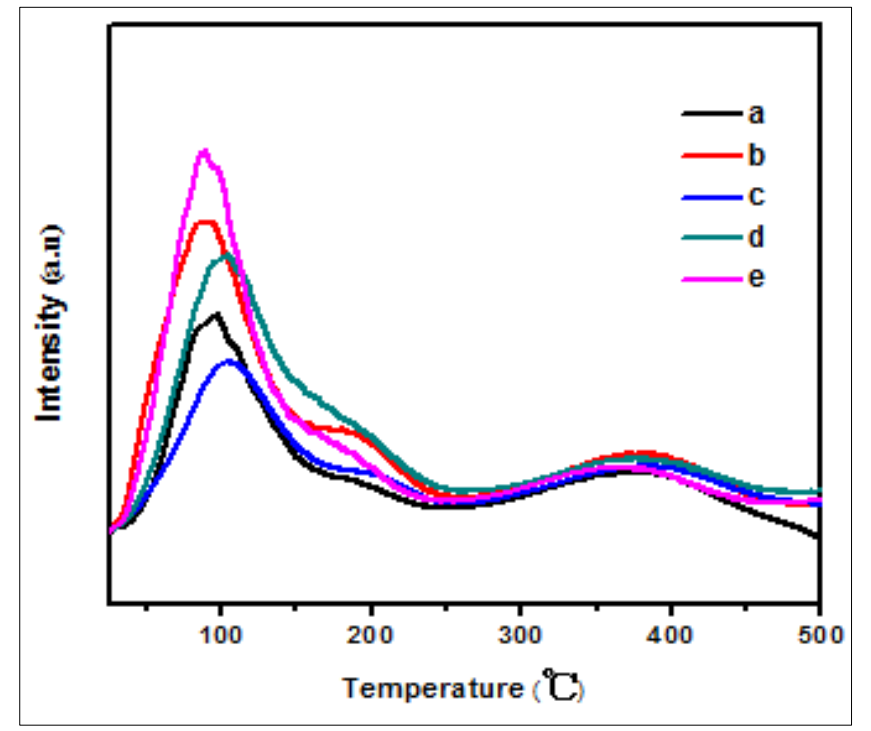

Figure 4. $\mathrm{NH}_{3}$-TPD profiles of (a) HZSM-5, (b) H[P, Al]-ZSM-5(0.2), (c) H[P, Al]-ZSM$5(0.4)$, (d) H[P, Al]-ZSM-5(0.6) and (e) H[P, Al]-ZSM-5(0.8) 


\subsection{Catalytic performance evaluation}

Table S3 showed the effect of $\mathrm{P}$ species content on the catalysis activity of $\mathrm{H}[\mathrm{P}, \mathrm{Al}]-\mathrm{ZSM}-5$ in coupling transformation of methanol with 1-butene to propylene. Under the condition of reaction temperature at $550^{\circ} \mathrm{C}$, molar ratio of methanol/1-butene to 1.0 , reaction pressure at $0.1 \mathrm{MPa}$ and $\mathrm{TOS}=$ $2 \mathrm{~h}$, the product distribution was shown in Figure S2. It can be seen that there is a difference in product distribution among five catalysts and exhibits the similar selectivity trend towards $\mathrm{CH}_{4}, \mathrm{C}_{2} \mathrm{H}_{6}, \mathrm{C}_{3} \mathrm{H}_{8}$ and $\mathrm{C}_{5}{ }^{+}$. However, the yield of ethene is increased with the $\mathrm{P}$ species content increased to 0.2 and then begin to drop with the increase of P-loading. It can be found that the selectivity of $\mathrm{C}_{5}{ }^{+}$is decreased with the increase of $\mathrm{P}$ species content from 0 to 0.4 and the reverse trend is observed with the increase of $\mathrm{P}$ species content from 0.4 to 0.8 . HZSM-5 modified with $\mathrm{P}$ species content of 0.4 has the lower selectivity of $\mathrm{C}_{5}{ }^{+}$, which means this catalyst has a lower steric limitation, lower coke formation and is beneficial for the coupling transformation of methanol with 1-butene to propylene [26]. Therefore, the product distribution on catalysts differs with different $\mathrm{P}$ species addition. Similarly, the selectivity of propylene among five catalysts generally shows the same trend compared to the selectivity of $\mathrm{C}_{5}{ }^{+}$. The P/E (propene/ethene) ratio can be used to indicate the presence of mesopores in the catalyst [27]. As shown in Figure S3, the lower P/E ratio is obtained on HZSM-5 modified with P species, this may be due to the P species located in pores or surfaces on the HZSM-5 catalyst.

In addition, as shown in Figure 5, the selectivity of $\mathrm{C}_{5}{ }^{+}$on HZSM-5 and H[P, Al]-ZSM-5(0.4) is increased within $8 \mathrm{~h}$. Most interesting, the selectivity of $\mathrm{C}_{5}{ }^{+}$on HZSM-5 is higher than on H[P, Al]ZSM-5(0.4), which may be due to this catalyst do not provide enough active sites for coupling transformation of methanol with 1-butene to propylene, accelerate the rate of coke formation, the bulky molecular substances are not immediately escaped from the inner microporous pores and accumulated on the active sites, resulting deactivation for the HZSM-5 zeolite [28].

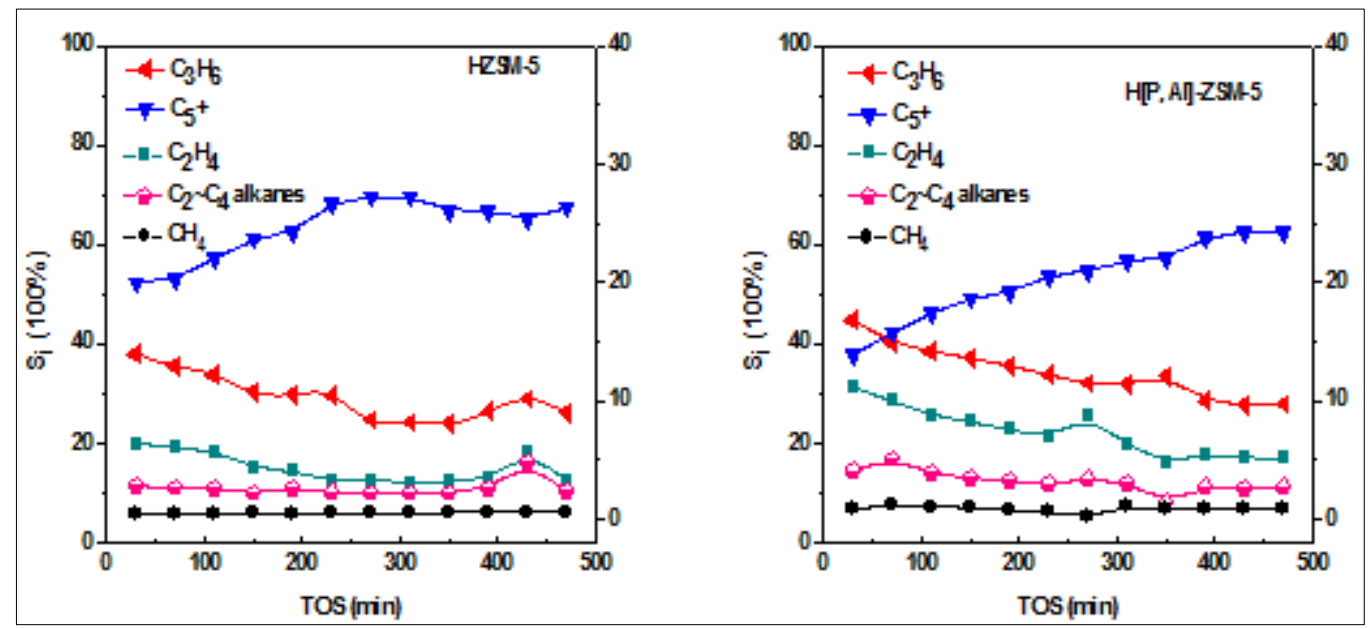

Figure 5. Selectivity of products versus time-on-stream on (a) HZSM-5 and (b) $\mathrm{H}[\mathrm{P}, \mathrm{Al}]-\mathrm{ZSM}-5(0.4)$ catalysts

As shown in Figure 6, the carbon deposition behavior of five spent catalysts was investigated by TG analysis after TOS of $8 \mathrm{~h}$ in the coupling transformation of methanol with 1-butene to propylene. It can be seen that the mass losses of the catalysts in the air atmosphere at temperature 323-1073 K is related to the combustion of deposited carbonaceous on the parent and modified HZSM-5 zeolite. In detail, two different weight loss temperature range is observed at $25-200^{\circ} \mathrm{C}$ and $500-700^{\circ} \mathrm{C}$, which are attributed to the removal of the physically adsorbed water in the catalyst, and the combustion of deposited carbonaceous, respectively. Considering the total reaction running time, the average rate of coke formation order is corresponding to: $\mathrm{H}[\mathrm{P}, \mathrm{Al}]-\mathrm{ZSM}-5(0.6)>\mathrm{H}[\mathrm{P}, \mathrm{Al}]-\mathrm{ZSM}-5(0.8)>\mathrm{H}[\mathrm{P}, \mathrm{Al}]-\mathrm{ZSM}-$ 5(0.2) > HZSM-5 > H[P, Al]-ZSM-5(0.4).The H[P, Al]-ZSM-5(0.4) exhibits a lowest average rate of coke formation, this further implies that the $\mathrm{H}[\mathrm{P}, \mathrm{Al}]-\mathrm{ZSM}-5(0.4)$ owns higher ability to coke tolerance 
and thus exhibits good catalytic performance. As mentioned above, the H[P, Al]-ZSM-5(0.4) has the lower concentration of medium-strong acid sites and the higher concentration of weak acid sites compared to the other four catalysts, which infers that H[P, Al]-ZSM-5(0.4) has lower initial reaction rate and the coke formation rate. Therefore, the pore opening, inner zeolite channels and external surfaces are not easily blocked by the coke deposition, which results in the full utilization of internal active sites of the zeolite and in turn, makes sure the long-term maintenance for the catalytic activity. The catalytic performance result shows that H[P, Al]-ZSM-5(0.4) exhibits the highest selectivity of propylene of $35.2 \%$.

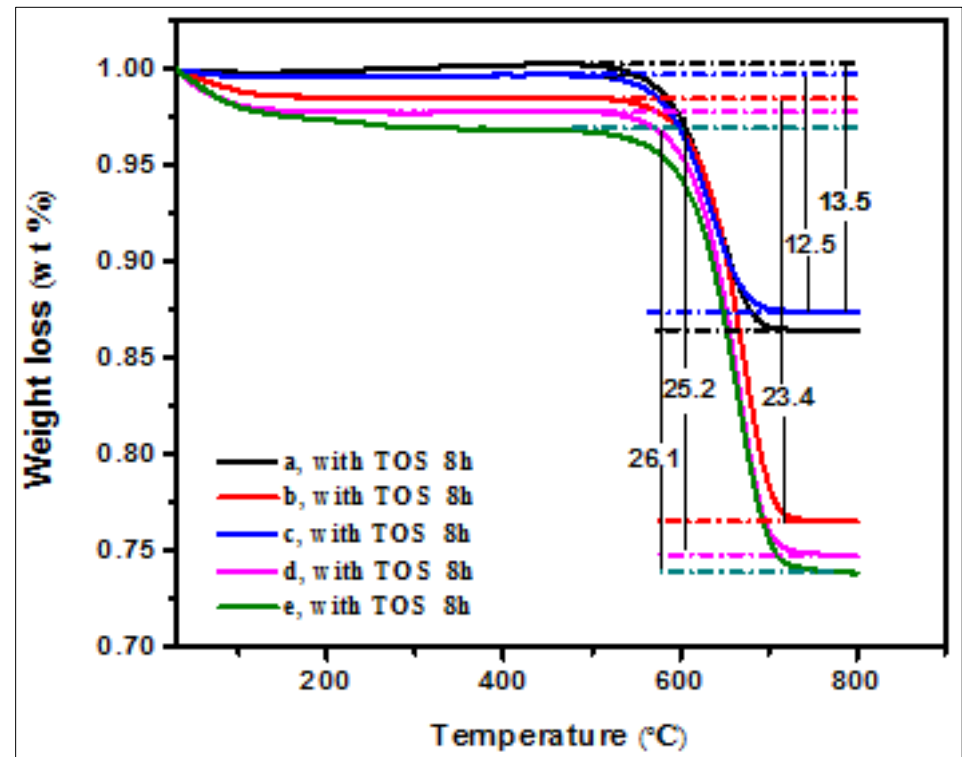

Figure 6. TG curves of (a) HZSM-5, (b) H[P, Al]-ZSM-5(0.2),

(c) H[P, Al]-ZSM-5(0.4), (d) H[P, Al]-ZSM-5(0.6) and (e) H[P, Al]-ZSM-5(0.8)

For the sake of obtaining catalysts with higher catalytic stability and better performance, $\mathrm{H}[\mathrm{P}, \mathrm{Al}]-$ ZSM-5(0.4) has been further evaluated at different temperatures. Figure 7 shows the effect of temperature on 1-butene conversion and product distribution on $\mathrm{H}[\mathrm{P}, \mathrm{Al}]-\mathrm{ZSM}-5(0.4)$. Overall the studied catalysts, methanol is almost completely converted during the investigated temperature range from 475 to $575^{\circ} \mathrm{C}$ and the conversion of 1-butene at different temperatures is up to $85 \%$. The selectivity of $\mathrm{CH}_{4}, \mathrm{C}_{2} \mathrm{H}_{6}$ and $\mathrm{C}_{3} \mathrm{H}_{8}$ reaches the same tendency with the increase of temperature, respectively. The selectivity trend of ethene is hardly changed from 475 to $525^{\circ} \mathrm{C}$. However, it is increases to the maximum value at $550^{\circ} \mathrm{C}$ and then decreases with the increase of the temperature. The selectivity of $\mathrm{C}_{5}{ }^{+}$shows the reverse tendency with the increase of the temperature compared to ethene. Moreover, as shown in Figure 10 , it can be seen that the selectivity of propylene is initially increases with the increase of temperature, reaching the maximum value at $550^{\circ} \mathrm{C}$, and subsequently decreases with the increase of the temperature .High propylene selectivity is obtained in this coupling reaction, which may be ascribed to that the fit higher temperature is beneficial for the transformation of methanol with 1-butene. In general, propylene could further transfer to side products by side reactions such as hydrogen transfer, oligomerization and aromatization at higher temperatures [29]. Therefore, under the condition ofmolar ratio of methanol/1butene to 1.0 , reaction pressure at $0.1 \mathrm{MPa}$ and $\mathrm{WHSV}=3.53 \mathrm{~h}^{-1}$, the temperature of $550{ }^{\circ} \mathrm{C}$ is best suited for the transformation of methanol with 1-butene to propylene. 

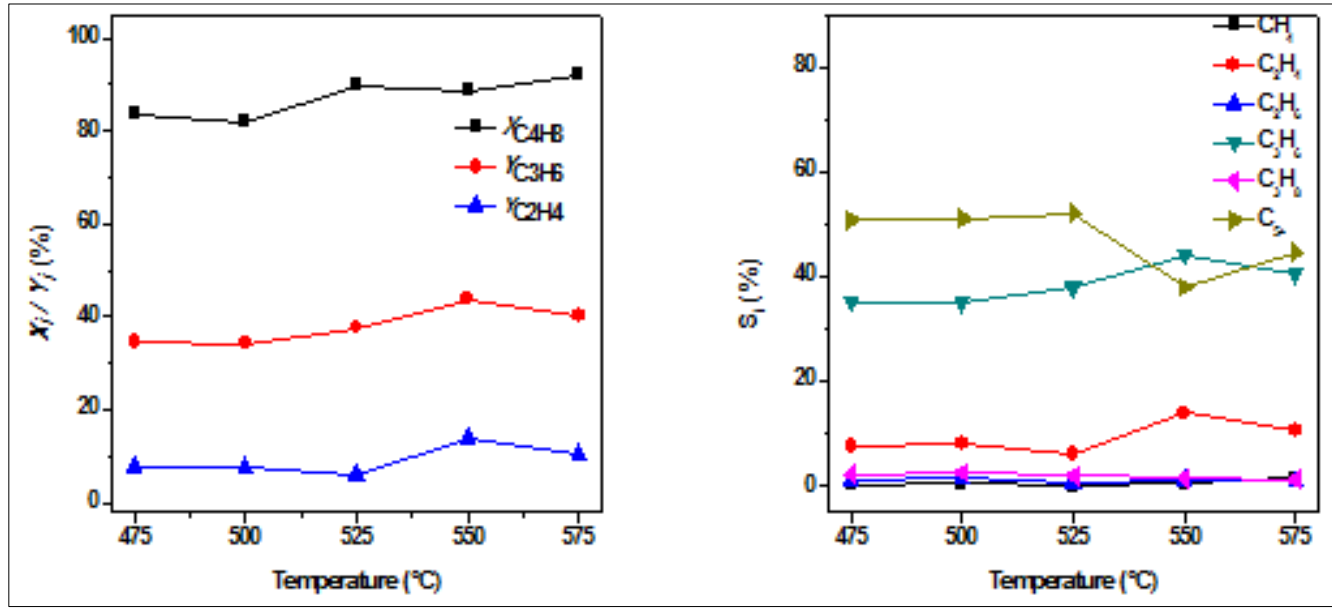

Figure 7. Effect of reaction temperature on (a) 1-butene conversion and (b) product distribution of P- modified ZSM-5 zeolite catalysts

Similarly, at the temperature of $550^{\circ} \mathrm{C}$, the effect of WHSV on 1-butene conversion and product distribution over H[P, Al]-ZSM-5(0.4) was shown in Figure 8. The conversion of 1-butene is completely maintained up to $85 \%$ at different WHSV. The selectivity of $\mathrm{CH}_{4}, \mathrm{C}_{2} \mathrm{H}_{6}$ and $\mathrm{C}_{3} \mathrm{H}_{8}$ is almost no change with the increase of WHSV, respectively. At WHSV of $3.53 \mathrm{~h}^{-1}$, the maximum selectivity of ethene and propylene was obtained, and the selectivity of $\mathrm{C}_{5}{ }^{+}$is lower than other points. Besides, the trend of propylene selectivity shows the reverse change compared to the product of $\mathrm{C}_{5}{ }^{+}$, which may be due to proper WHSV is beneficial for the selectivity of propylene and could provide enough opportunity for the contact of the reactant with the active sites. In addition, the selectivity of propylene and $\mathrm{C}_{5}{ }^{+}$varies with the increase of WHSV, this may be inferred that the product distribution is closely related to WHSV. Thus, to enhance the selectivity of propylene, the fit WHSV has to be considered in the coupling transformation of methanol with 1-butene to propylene.
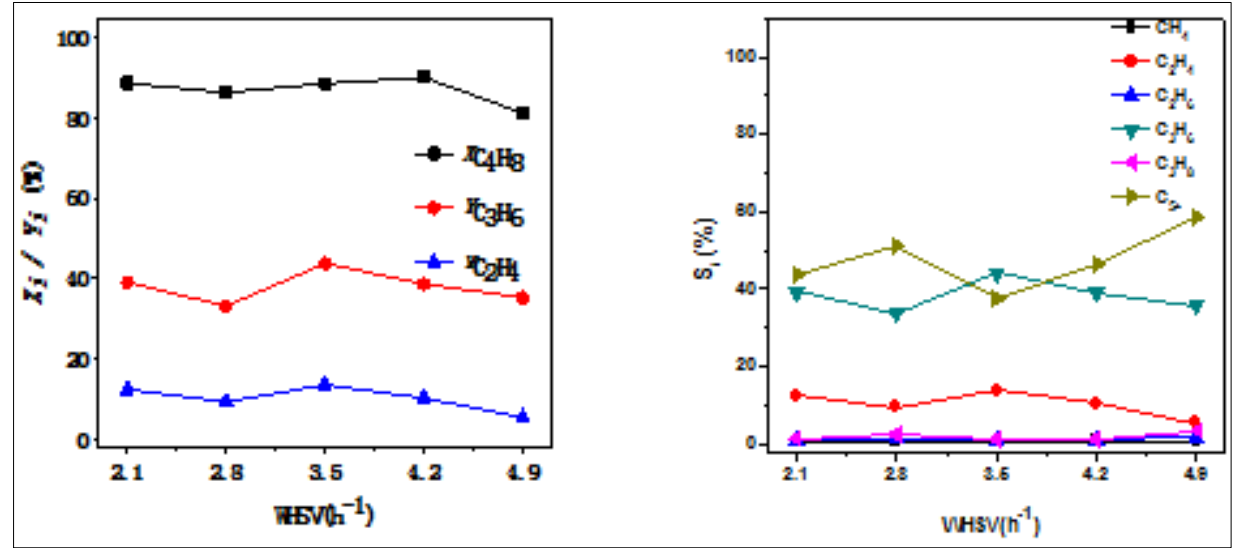

Figure 8. Effect of WHSV on (a) 1-butene conversion and (b) product distribution of modified ZSM-5 zeolite catalysts

Figure 9 shows the effect of molar ratio of methanol to1-butene on 1-butene conversion and product distribution over H[P, Al]-ZSM-5(0.4).For this coupling reaction, the selectivity of propylene and ethene initially increases and then decreases with the increase of methanol/1-butene molar ratio. According to the test of catalytic performance on H[P, Al]-ZSM-5(0.4), it can be found that the highest selectivity of propylene and ethene is obtained at methanol/1-butene molar ratio of 1.0. 


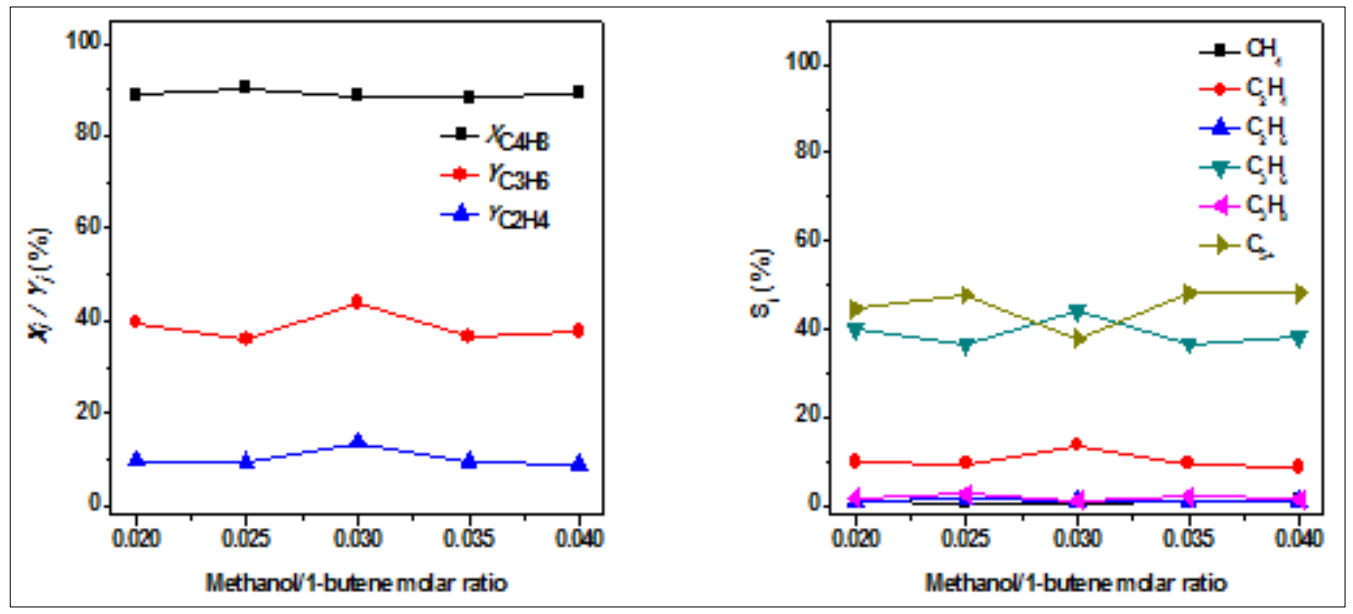

Figure 9. Effect of methanol/1-butene molar ratio on (a) 1-butene conversion and (b) product distribution of $\mathrm{H}[\mathrm{P}, \mathrm{Al}]-\mathrm{ZSM}-5(0.4)$ zeolite catalysts

$\mathrm{H}[\mathrm{P}, \mathrm{Al}]-\mathrm{ZSM}-5$ catalyst is successfully synthesized by the isomorphous hydrothermal method. In detail, the addition of $\mathrm{P}$ species into the HZSM-5 structure could facilitate the breaking of Si-O-Al bond and the total concentration of acid sites is reduced according to the TPD measurement using $\mathrm{NH}_{3}$ as a probe molecule [30]. From the analysis of the FT-IR test, P species is successfully introduced into the parent HZSM-5 structure at the vibrational band near 634 and $592 \mathrm{~cm}^{-1}$. Combining these three aspects, this implies that the framework $\mathrm{Al}$ (FAl) is partially replaced by $\mathrm{P}$ species. In addition, according to the analysis from ICP-OES test, as shown in table S1, we speculate P species may partially substitute with framework $\mathrm{Al}(\mathrm{FAl})$.There are no $\mathrm{Al}$ or P species on external surfaces of the P-modified ZSM-5, however, these two species can be found in the core or framework of catalysts. Moreover, it can be found from the SEM image analysis, four catalysts except the H[P, Al]-ZSM-5(0.8) show the same spherical morphology,and exhibit different selectivity of product distribution in this study, especially for the selectivity of propylene and ethene. In addition, from the analysis of TG-DTA test, five catalysts demonstrate different coke tolerance, which is possibly associating with the diffusion limitation of catalyst structure [31].

In order to shed light on the catalytic stability and higher selectivity of propylene on P-modified ZSM-5, the selectivity of the product distribution mechanism was studied.It is well-known that the transformation of methanol with 1-butene to propylene on P-modified HZSM-5 follows the hydrocarbon pool mechanism, many reactions participate in coupling reaction such as the hydrogen transfer, cracking, isomerization, oligomerization, alkylation and so on. Generally, propylene is obtained by the cracking of 1-butene dimers and then maybe further transferred to secondary reactants such as $\mathrm{C}_{5}^{+}[10]$. According to the category of hydrocarbon pool (HCP) species, the HCP mechanism can be further divided into aromatic-based and alkene-based two cycles [32]. In the aromatic-based cycle, polymethylbenzenes (polyMBs) usually produce ethylene and propylene through olefin elimination and methanol methylation [33]. The alkene-based cycle is based on the repeated methylation and cracking of $\mathrm{C}_{3}{ }^{+}$alkenes [34]. In general, ethene, propylene and aromatics are the main product in the aromatic-based cycle, however, the alkene-based cycle produces the main product of propylene and higher alkenes. In this study, under the same conditions, five catalysts exhibit different product distribution after time-on-stream of $2 \mathrm{~h}$ in coupling transformation of methanol with 1-butene, this infers that the two aromatic-based and olefinbased cycles may vary on the catalyst with a different structure. Moreover, for the same catalyst, such as $\mathrm{H}[\mathrm{P}, \mathrm{Al}]-\mathrm{ZSM}-5(0.4)$, its product distribution may vary with the different conditions of reaction temperature, WHSV and methanol/1-butene molar ratio.

The possible pathway on $\mathrm{H}[\mathrm{P}, \mathrm{Al}]-\mathrm{ZSM}-5(0.4)$ in the coupling transformation of methanol with 1butene to propylene often refers to as follows: methanol is initially transferred to methoxy species and 1 -butene is changed to carbenium ion following the biomolecular reactions. Methoxy species reacts with 
carbenium ion to produce olefins [17], The reaction mechanism is shown in scheme 1. However, propylene and ethene could easily transfer to secondary products by hydrogen transfer, isomerization, and aromatization if there is a higher concentration of medium and strong acid sites on the catalyst, which implies that the type of acid sites play an important role in product distribution. Therefore, in order to enhance the selectivity of propylene, the moderate acid sites is taken into account. In this study, $\mathrm{P}$ species is used to modify the acidity of the catalyst, which in turn affects the product distribution. The catalytic performance test indicates that $\mathrm{H}[\mathrm{P}, \mathrm{Al}]-\mathrm{ZSM}-5(0.4)$ modified with $\mathrm{P}$ species exhibits higher selectivity of propylene, which may due to its moderate density and distribution of acid sites.

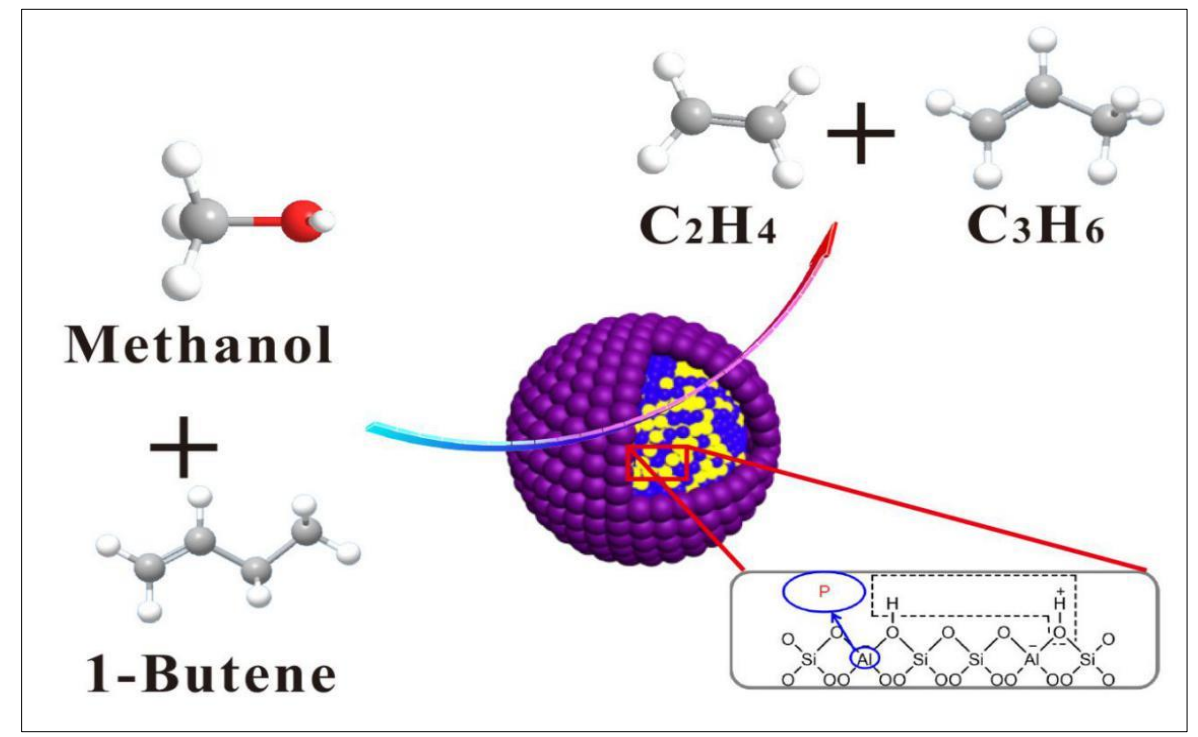

Scheme 1. The scheme of isomorphous substituted method of introducing

$\mathrm{P}$ into ZSM-5 framework and catalytic performance over a series of

$\mathrm{H}[\mathrm{P}, \mathrm{Al}]-\mathrm{ZSM}-5$ in coupling methanol with 1-butene

\section{Conclusions}

HZSM-5 zeolites with different $\mathrm{P}$ species content were synthesized by isomorphous substitution method. The acidity of parent HZSM-5 is changed after modified by $\mathrm{P}$ species. The medium and strong acidity on $\mathrm{H}[\mathrm{P}, \mathrm{Al}]-\mathrm{ZSM}-5(0.4)$ decrease compared to parent HZSM-5 zeolite. The catalytic performance result shows that $\mathrm{H}[\mathrm{P}, \mathrm{Al}]-\mathrm{ZSM}-5(0.4)$ is an efficient catalyst in the transformation of methanol with 1butene to propylene.Under the condition of reaction temperature at $550^{\circ} \mathrm{C}$, molar ratio of methanol/1butene to1.0, reaction pressure at $0.1 \mathrm{MPa}$ and $\mathrm{WHSV}=3.53 \mathrm{~h}^{-1}$, the selectivity of propylene is up to $35.6 \%$. Moreover, H[P, Al]-ZSM-5(0.4) exhibits the lower rate of coke formation.

Acknowledgments. The authors express their gratitude for the Nature Science Fund of China (No.21865031) and the Young Teacher Research Group Foundation of Northwest Normal University (NWNU-LKQN-16-6).

\section{Reference}

1. Z. WANG, G. JIANG, Z. ZHAO, X. FENG, A. DUAN, J. LIU, C. XU, J. GAO, Highly Efficient PModified HZSM-5 Catalyst for the Coupling Transformation of Methanol and 1-Butene to Propene, Energy Fuel, 24, 2010, 758-763.

2. E. EPELDE, A.G. GAYUBO, M. OLAZAR, J. BILBAO, A.T. AGUAYO, Intensifying Propylene Production by 1-Butene Transformation on a K Modified HZSM-5 Zeolite-Catalyst, Ind. Eng. Chem. Res, 53, 2014, 4614-4622. 
3. X. ZHU, X. LI, S. XIE, S. LIU, G. XU, W. XIN, S. HUANG, L. XU, Two New On-Purpose Processes Enhancing Propene Production: Catalytic Cracking of $\mathrm{C}_{4}$ Alkenes to Propene and Metathesis of Ethene and 2-Butene to Propene, Catal Surv Asia, 13, 2008, 1.

4. F. LIU, X. WANG, F. XU, Q. LIN, H. PAN, H. WU, J. CAO, Fabrication and characterization of composites comprising (CHA)SAPO-34 with (MFI)ZSM-5 topologies and their catalytic performances on MTO reaction, Micropor Mesopor Mat, 252, 2017, 197-206.

5.J. LV, Z. HUA, T. GE, J. ZHOU, J. ZHOU, Z. LIU, H. GUO, J. SHI, Phosphorus modified hierarchically structured ZSM-5 zeolites for enhanced hydrothermal stability and intensified propylene production from 1-butene cracking, Micropor Mesopor Mat, 247, 2017, 31-37.

6.E. EPELDE, A.G. GAYUBO, M. OLAZAR, J. BILBAO, A.T. AGUAYO, Modified HZSM-5 zeolites for intensifying propylene production in the transformation of 1-butene, Chem. Eng. J., 251 ,2014, 8091.

7.VAlle, B., AlONSO, A., ATUTXA, A., GAYUBO, A.G., BILBAO. J., Effect of nickel incorporation on the acidity and stability of HZSM-5 zeolite in the MTO process, Catal .Today, 106(1), $2005,118-22$.

8.R. FENG, X. YAN, X. HU, Z. YAN, J. LIN, Z. LI, K. HOU, M.J. ROOD, Surface dealumination of micro-sized ZSM-5 for improving propylene selectivity and catalyst lifetime in methanol to propylene (MTP) reaction, Catal Commun, 109, 2018, 1-5.

9.J. LI, Y. QI, L. XU, G. LIU, S. MENG, B. LI, M. LI, Z. LIU, Co-reaction of ethene and methanol over modified H-ZSM-5, Catal Commun, 9, 2008, 2515-2519.

10.J. LU, Z. ZHAO, C. XU, A. DUAN, X. WANG, P. ZHANG, Catalytic cracking of isobutane over HZSM-5, FeHZSM-5 and CrHZSM-5 catalysts with different $\mathrm{SiO}_{2} / \mathrm{Al}_{2} \mathrm{O}_{3}$ ratios, J. Porous Mater, 15, 2008, 213-220.

11.Y. SONG, L.-L. ZHANG, G.-D. LI, Y.-S. SHANG, X.-M. ZHAO, T. MA, L.-M. ZHANG, Y.-L. ZHAI, Y.-J. GONG, J. XU, F. DENG, ZSM-5 extrudates modified with phosphorus as a super effective MTP catalyst: Impact of the acidity on binder, Fuel Process. Technol, 168, 2017, 105-115.

12.T. GONG, X. ZHANG, T. BAI, Q. ZHANG, L. TAO, M. QI, C. DUAN, L. ZHANG, Coupling Conversion of Methanol and C4 Hydrocarbon to Propylene on La-Modified HZSM-5 Zeolite Catalysts, Ind. Eng. Chem. Res, 51, 2012, 13589-13598.

13.J. LU, Z. ZHAO, C. XU, P. ZHANG, A. DUAN, FeHZSM-5 molecular sieves - Highly active catalysts for catalytic cracking of isobutane to produce ethylene and propylene, Catal. Commun, 7, 2006, 199-203.

14.BLASCO, T., CORMA, A., MARTÍNEZ-TRIGUERO, J., Hydrothermal stabilization of ZSM-5 catalytic-cracking additives by phosphorus addition, J. Catal, 237, 2006, 267-277.

15. G. ZHAO, J. TENG, Z. XIE, W. JIN, W. YANG, Q. CHEN, Y. TANG, Effect of phosphorus on HZSM-5 catalyst for C4-olefin cracking reactions to produce propylene, J. Catal, 248, 2007, 29-37.

16. G.Q. ZHANG, T. BAI, T.F. CHEN, W.T. FAN, X. ZHANG, Conversion of Methanol to Light Aromatics on Zn-Modified Nano-HZSM-5 Zeolite Catalysts, Ind. Eng. Chem. Res, 53, 2014, 1493214940.

17. X. SU, G. WANG, X. BAI, W. WU, L. XIAO, Y. FANG, J. ZHANG, Synthesis of nanosized HZSM5 zeolites isomorphously substituted by gallium and their catalytic performance in the aromatization, Chem. Eng. J., 293, 2016, 365-375.

18. M. ROSTAMIZADEH, A. TAEB, Highly selective Me-ZSM-5 catalyst for methanol to propylene (MTP), J. Ind. Eng, 27, 2015, 297-306.

19. P. LOSCH, G. LAUGEL, J.S. MARTINEZ-ESPIN, S. CHAVAN, U. OLSBYE, B. LOUIS, Phosphorous Modified ZSM-5 Zeolites: Impact on Methanol Conversion into Olefins, Top. Catal, 58, 2015, 826-832.

20. J. LIU, C. ZHANG, Z. SHEN, W. HUA, Y. TANG, W. SHEN, Y. YUE, H. XU, Methanol to propylene: Effect of phosphorus on a high silica HZSM-5 catalyst, Catal. Commun, 10, 2009, 1506-1509. 
21. X. YANG, F. WANG, R. WEI, S. LI, Y. WU, P. SHEN, H. WANG, L. GAO, G. XIAO, Synergy effect between hierarchical structured and Sn-modified H[Sn, Al]ZSM-5 zeolites on the catalysts for glycerol aromatization, Micropor Mesopor Mat., 257, 2018, 154-161.

22. SAZAMA, P., DĚDEČEK, J., GÁBOVÁ, V., WICHTERLOVÁ, B., SPOTO, G., BORDIGA, S., Effect of aluminium distribution in the framework of ZSM-5 on hydrocarbon transformation. Cracking of 1-butene, J. Catal. 254, 2008, 180-189.

23. Y.-Q. SONG, Y.-L. FENG, F. LIU, C.-L. KANG, X.-L. ZHOU, L.-Y. XU, G.-X. YU, Effect of variations in pore structure and acidity of alkali treated ZSM-5 on the isomerization performance, $J \mathrm{Mol}$ Catal A-Chem, 310, 2009, 130-137.

24. Y. JI, H. YANG, Q. ZHANG, W. YAN, Phosphorus modification increases catalytic activity and stability of ZSM-5 zeolite on supercritical catalytic cracking of n-dodecane, J. Solid State Chem, 251, 2017, 7-13.

25. X. LIN, Y. FAN, Z. LIU, G. SHI, H. LIU, X. BAO, A novel method for enhancing on-stream stability of fluid catalytic cracking (FCC) gasoline hydro-upgrading catalyst: Post-treatment of HZSM-5 zeolite by combined steaming and citric acid leaching, Catal. Today, 125, 2007, 185-191.

26. A.T. AGUAYO, D. MIER, A.G. GAYUBO, M. GAMERO, J. BILBAO, Kinetics of Methanol Transformation into Hydrocarbons on a HZSM-5 Zeolite Catalyst at High Temperature $\left(400-550^{\circ} \mathrm{C}\right)$, Ind. Eng. Chem. Res, 49, 2010, 12371-12378.

27. C. MEI, P. WEN, Z. LIU, H. LIU, Y. WANG, W. YANG, Z. XIE, W. HUA, Z. GAO, Selective production of propylene from methanol: Mesoporosity development in high silica HZSM-5, J. Catal, 258, 2008, 243-249.

28. Y. YANG, C. SUN, J. DU, Y. YUE, W. HUA, C. ZHANG, W. SHEN, H. XU, The synthesis of endurable B-Al-ZSM-5 catalysts with tunable acidity for methanol to propylene reaction, Catal. Commun, 24, 2012, 44-47.

29. P. ARUDRA, T.I. BHUIYAN, M.N. AKHTAR, A.M. AITANI, S.S. AL-KHATTAF, H. HATTORI, Silicalite-1 As Efficient Catalyst for Production of Propene from 1-Butene, ACS Catal, 4, 2014, 42054214.

30. K. RAMESH, C. JIE, Y.-F. HAN, A. BORGNA, Synthesis, Characterization, and Catalytic Activity of Phosphorus Modified H-ZSM-5 Catalysts in Selective Ethanol Dehydration, Chem. Res, 49, 2010, 4080-4090.

31. C.H. CHRISTENSEN, I. SCHMIDT, A. CARLSSON, K. JOHANNSEN, K. HERBST, Crystals in CrystalsNanocrystals within Mesoporous Zeolite Single Crystals, J. Am. Chem. Soc, 127, 2005, 80988102.

32. L. LIN, C. QIU, Z. ZHUO, D. ZHANG, S. ZHAO, H. WU, Y. LIU, M. HE, Acid strength controlled reaction pathways for the catalytic cracking of 1-butene to propene over ZSM-5, J. Catal., 309, 2014, 136-145.

33. A. SASSI, M.A. WILDMAN, H.J. AHN, P. PRASAD, J.B. NICHOLAS, J.F. HAW, Methylbenzene Chemistry on Zeolite HBeta: Multiple Insights into Methanol-to-Olefin Catalysis, J. Phys. Chem, 106, 2002, 2294-2303.

34. T. LIANG, J. CHEN, Z. QIN, J. LI, P. WANG, S. WANG, G. WANG, M. DONG, W. FAN, J. WANG, Conversion of Methanol to Olefins over H-ZSM-5 Zeolite: Reaction Pathway is Related to the Framework Aluminum Siting, ACS Catal, 6, 2016, 7311-7325.

Manuscript received: 03.09 .2020 